\title{
PERAN SOCIAL MATURITY DALAM MEMBANGUN SCHOOL READINESS PADA MURID PRASEKOLAH KAYATA SCHOOL BERASTAGI
}

\author{
Yulinda Septiani Manurung \\ Program Studi Psikologi \\ Fakultas Psikologi Universitas Prima Indonesia \\ (yulindaseptianimanurung@unprimdn.ac.id) \\ Winida Marpaung \\ Program Studi Psikologi \\ Fakultas Psikologi Universitas Prima Indonesia \\ (winidamarpaung@unprimdn.acid)
}

\begin{abstract}
This study aims to see how the readiness of preschool children to enter primary school, especially their social maturity. The subjects of the study were 15 Berastagi Kayata School preschoolers aged four to seven year old. Data was taken with the Nijmeegse Schoolbekwaamheidstest (NST) test to obtain a picture of children's school readiness and the Vineland Adaptive Behavior Scale (VABS) to look more specifically at a child's social maturity. The research data were analyzed descriptively with a quantitative approach. The results obtained in this study are as the chronological age of Kayata School preschoolers become more mature, they are intellectually ready to enter elementary school. But socially and emotionally, their readiness is still not optimal to be able to participate in learning activities in elementary schools
\end{abstract}

Keywords : School readiness, Social Maturity

\section{PENDAHULUAN}

Orangtua selalu berkeinginan untuk memberikan yang terbaik bagi anak-anaknya termasuk dalam hal pendidikan. Setiap tahunnya, menjelang tahun ajaran baru, para orangtua sibuk mencari informasi tentang sekolah, mulai dari mengumpulkan brosur untuk mengenal profil sekolah, meninjau lingkungan sekitar sekolah, mencari informasi mengenai fasilitas, kedisiplinan, jarak lokasi sekolah dari rumah, dsb.

Pendidikan adalah hak setiap manusia. Hal ini ditegakkan dalam UUD 1945 Pasal 31 yang berisi tentang "Setiap warga negara berhak mendapat pendidikan". Pada hakekatnya, pendidikan adalah salah satu kebutuhan utama dalam kehidupan manusia. Bagaimana kualitas manusia sangat dipengaruhi oleh pendidikan yang diterimanya. 
Untuk menciptakan generasi yang berkualitas, pendidikan harus dilakukan sejak usia dini, dalam hal ini melalui Pendidikan Anak Usia Dini (PAUD), yaitu pendidikan yang ditujukan bagi anak sejak lahir hingga usia 6 tahun. Dalam Peraturan Mendikbud Republik Indonesia Nomor 146 Tahun 2014 Tentang Kurikulum 2013 PAUD disebutkan bahwa salah satu layanan PAUD adalah berupa Taman Kanak-kanak (TK) yang ditujukan untuk anak berusia 4 (empat) sampai dengan 6 (enam) tahun.

Kondisi peralihan dari TK ke Sekolah Dasar (SD) adalah satu fase yang tidak mudah. Hal ini merupakan satu langkah besar bagi anak, karena di sekolah, besar tuntutan yang dterima anak akan berbeda dengan saat anak tersebut berada di Taman Kanak-kanak. Sabri (dalam Novitawati, 2011) mengemukakan bahwa anak-anak yang pernah mengikuti program TK, secara fisik, intelektual, dan fungsi sosial, lebih siap memasuki kelas satu SD.

Namun, pada kenyataannya, masih sering ditemukan keluhan dari orangtua bahwa anak belum bisa dilepas untuk belajar sendiri ketika masuk ke SD, masih tampak seperti anak TK yang perlu dibantu untuk menata pakaian dan perlengkapan sekolah, masih perlu ditunggui untuk menyelesaikan tugas rumah, dan banyak lagi.

Hasil penelitian Sembiring (2013) mengenai kesiapan sekolah anak menunjukkan bahwa $82 \%$ anak sudah cukup mampu untuk menyesuaikan diri, $84 \%$ sudah cukup terampil bersosialisasi, $68 \%$ sudah cukup mampu untuk mengendalikan diri, namun hanya $50 \%$ yang sudah cukup mandiri, dengan $68,75 \%$ belum terampil untuk mandi sendiri, $65,625 \%$ belum terampil untuk membersihkan diri setelah buang air besar, dan $56,25 \%$ belum terampil untuk berpakaian sendiri.

Kondisi ini membuat peneliti tertarik untuk melihat bagaimana kesiapan sekolah anak TK dalam memasuki SD khususnya kematangan sosialnya. Penelitian ini diharapkan dapat membantu guru dalam menyusun pembelajaran serta memberikan informasi pada orangtua/wali tentang kemajuan pertumbuhan dan perkembangan anak.

\section{Kesiapan Sekolah}

Lerner (1997) menjelaskan bahwa konsep kesiapan (readiness) berkaitan dengan kondisi perkembangan kematangan dan pengalaman sebelumnya yang diperlukan sebelum suatu keterampilan tertentu dapat dipelajari. Pengalaman dan kematangan yang dimaksudkan di sini bisa meliputi tahap perkembangan susunan syaraf, kekuatan otot yang memadai, dan perkembangan lainnya.

Vygotsky (dalam Lerner, 1997) mengungkapkan teori tentang zone of proximal development, yang mendasari tentang teori kesiapan belajar. Terdapat beberapa tahap kesiapan dalam belajar. Tahapnya berkisar dari yang pertama adalah siswa dapat belajar hampir secara mandiri, hingga tahap terakhir, yaitu materinya berada di luar kemampuan anak, sehingga walau dengan petunjuk yang terstruktur sekalipun, siswa tidak akan dapat menguasai 
keterampilan yang diajarkan. Zona perkembangan yang sesuai berada dalam kisaran kedua tahap tersebut. Siswa tidak dapat memecahkan persoalan sendirian, namun dapat belajar dengan berhasil di bawah bimbingan orang dewasa atau berkolaborasi dengan teman yang lebih mampu.

Beberapa hal yang perlu dikuasai agar siap masuk sekolah yang dirumuskan Hurlock (1980), antara lain: kemampuan adaptasi, kemampuan menata dan merawat barang, pengendalian emosi, keterampilan motorik halus dan kasar, keterampilan menolong diri sendiri, dan keterampilan sosial. Secara umum, keterampilan tersebut dapat dibagi menjadi empat kategori, yakni menolong diri sendiri, menolong orang lain, keterampilan sekolah, dan keterampilan bermain.

\section{Kematangan Sosial}

Kematangan sosial merupakan kemampuan individu untuk mengurus dirinya dan berpartisipasi atau ikut serta dalam kegiatan yang mengarahkan pada kemandirian (Doll, 1965). Ada beberapa istilah yang sering digunakan untuk menyebut kematangan sosial, seperti kematangan atau kedewasaan sosial. Salah satunya adalah Chaplin (1989) yang mendefinisikan bahwa kematangan sosial merupakan suatu perkembangan keterampilan dan kebiasaan-kebiasaan individu yang menjadi ciri khas kelompoknya. Kematangan sosial juga dapat dilihat sebagai suatu indikator keberhasilan seorang anak dalam penyesuaian diri dengan lingkungan sekitar, baik terhadap orang lain maupun benda di sekitarnya. Perilaku yang berkaitan dengan kematangan sosial seseorang adalah komunikasi, keterampilan sehari-hari, sosialisasi dengan orang lain, dan kemampuan motorik (Sparrow, dkk., 1984).

\section{METODE PENELITIAN}

Penelitian ini menggunakan metode analisis deskriptif dengan pendekatan kuantitatif. Adapun pengertian deskriptif menurut Sugiyono (2012) adalah metode yang berfungsi untuk mendeskripsikan atau memberi gambaran terhadap objek yang diteliti melalui data atau sampel yang telah terkumpul sebagaimana adanya, tanpa melakukan analisis dan membuat kesimpulan yang berlaku umum. Termasuk dalam statistik deskriptif, antara lain: penyajian data melalui tabel, grafik, diagram lingkaran, pictogram, perhitungan modus, median, mean (pengukuran tendensi sentral), perhitungan desil, persentil, perhitungan penyebaran data melalui perhitungan rata-rata dan standar deviasi, perhitungan persentase (Sugiyono dalam Sudaryono, 2016).

Sampel diambil dari sebuah Pendidikan Anak Usia Dini (PAUD) Kayata School, sebuah prasekolah di Kecamatan Berastagi, Kabupaten Karo, Sumatera Utara. Jumlah sampel dalam penelitian ini adalah sebanyak 15 orang, yakni seluruh murid berusia 4 (empat) hingga 7 (tujuh) tahun yang aktif bersekolah di Kayata School. Pengambilan data dilakukan secara individual (1 orang tester, 1 orang murid) selama satu hari di bulan Mei 2019 yang berlangsung di Kayata School, Berastagi. Ada 6 (enam) orang tester yang terlibat untuk melakukan 
pengambilan data terhadap 15 orang murid dan 15 orang guru/wali/orangtua murid.

Variabel yang diteliti adalah kesiapan anak untuk masuk sekolah, yang didefinisikan secara operasional sebagai kesiapan sekolah yang meliputi kesiapan fisik, kesiapan intelektual, kesiapan sosial, dan kesiapan emosional; serta kematangan sosial anak yang mencakup: kemampuan berkomunikasi, keterampilan hidup sehari-hari, dan kemampuan bersosialisasi.

\section{Instrumen yang Digunakan}

Data diambil dengan alat tes Nijmeegse Schoolbekwaamheidstest (NST) yang diberikan langsung kepada anak untuk memperoleh gambaran kesiapan sekolah anak dan Vineland Adaptive Behavior Scale (VABS) yang ditanyakan kepada orangtua atau wali untuk melihat kematangan sosial anak secara lebih spesifik.

NST dibuat oleh Prof. Dr. F.J. Monks, Drs. H. Rost, Drs. N.H. Coffie, dengan tujuan untuk mengetahui tingkat kematangan anak memasuki pendidikan level sekolah dasar, prognosis (meramalkan) prestasi sekolah anak di sekolah dasar, dan mengetahui kemampuankemampuan tertentu anak yang sudah atau belum matang dan perlu latihan, pembinaan, pengembangan, atau peningkatan. Kesiapan sekolah yang dapat diketahui dari NST, antara lain: kesiapan fisik, kesiapan intelektual, kesiapan sosial, dan kesiapan emosional.
Sedangkan VABS merupakan adalah suatu alat pengukuran psikologi yang dirancang untuk mengukur perilaku adaptif individu mulai dari lahir hingga usia 90 tahun. VABS terdiri atas 5 domain, masingmasing dengan 2-3 subdomain. Kelima domain tersebut, antara lain: komunikasi, keterampilan hidup sehari-hari, sosialisasi, keterampilan motorik, dan perilaku adaptif (yang sifatnya opsional). Dalam penelitian ini, hanya 3 domain VABS yang hasilnya digunakan oleh peneliti, yakni domain komunikasi (terdiri dari subdomain: komunikasi reseptif, ekspresif, dan tertulis), domain keterampilan hidup sehari-hari (terdiri dari subdomain: personal, domestik, dan masyarakat), dan domain sosialisasi (terdiri dari subdomain: hubungan antar personil, bermain dan waktu senggang, serta keterampilan mengatasi).

\section{Pengolahan Data}

Data hasil tes NST akan diskor secara individual, kemudian dianalisa menggunakan teknik statistika dan diinput ke dalam tabel berdasarkan persentasenya, dengan kategori belum siap, ragu-ragu, dan siap untuk sekolah. Demikian pula data hasil penelitian menggunakan metode survei berdasarkan VABS. Data dianalisa dengan teknik statistika sederhana agar diperoleh gambaran bagaimana kematangan sosial anak yang akan memasuki sekolah dasar 


\section{HASIL dan PEMBAHASAN}

Berikut ini merupakan deskripsi

berdasarkan umur sebagai

karakteristik sampel:

Tabel 1. Karakteristik Sampel Penelitian Berdasarkan Usia

\begin{tabular}{|c|c|c|}
\hline $\begin{array}{c}\text { Umur } \\
\text { (Tahun) }\end{array}$ & $\begin{array}{c}\text { Jumlah } \\
\text { (Orang) }\end{array}$ & $\begin{array}{c}\text { Persentase } \\
(\%)\end{array}$ \\
\hline 4 & 6 & 40 \\
\hline 5 & 4 & 26,67 \\
\hline 6 & 4 & 26,67 \\
\hline 7 & 1 & 6,66 \\
\hline Total & 15 & 100 \\
\hline
\end{tabular}

Tabel 1 di atas menunjukkan bahwa sampel terbanyak, yaitu pada umur 4 tahun dengan jumlah 6 orang dan persentase $40 \%$. Sampel berumur 5 tahun ada 4 orang $(26,67 \%)$, sampel berusia 6 tahun ada 4 orang (26,67\%), dan jumlah yang paling sedikit ada pada sampel berusia 7 tahun, yakni hanya ada 1 orang $(6,66 \%)$.

Selanjutnya

peneliti mendeskripsikan hasil dari pemeriksaan kesiapan sekolah dan kematangan sosial berdasarkan usia masing-masing anak.

Tabel 2. Gambaran Hasil NST Murid Kayata School yang Berusia 4 Tahun

\begin{tabular}{|l|c|c|c|c|}
\hline Aspek NST & $\begin{array}{c}\text { Belum } \\
\text { Siap } \\
(\%)\end{array}$ & $\begin{array}{c}\text { Ragu } \\
(\%)\end{array}$ & $\begin{array}{c}\text { Siap } \\
\text { Untuk } \\
\text { Sekolah } \\
(\%)\end{array}$ & $\begin{array}{c}\text { Total } \\
(\%)\end{array}$ \\
\hline $\begin{array}{l}\text { Pengamatan } \\
\text { Bentuk dan } \\
\text { Kemampuan } \\
\text { Membedakan }\end{array}$ & 0 & 0 & 100 & 100 \\
\hline $\begin{array}{l}\text { Motorik } \\
\text { Halus }\end{array}$ & 50 & 0 & 50 & 100 \\
\hline $\begin{array}{l}\text { Pengertian } \\
\text { Tentang } \\
\text { Besar Jumlah } \\
\text { dan }\end{array}$ & 50 & 0 & 50 & 100 \\
\hline
\end{tabular}

\begin{tabular}{|l|c|c|c|c|}
\hline Perbandingan & & & & \\
\hline $\begin{array}{l}\text { Pengamatan } \\
\text { Tajam }\end{array}$ & 0 & 16,67 & 83,33 & 100 \\
\hline $\begin{array}{l}\text { Pengamatan } \\
\text { Kritis }\end{array}$ & 0 & 16,67 & 83,33 & 100 \\
\hline Konsentrasi & 0 & 0 & 100 & 100 \\
\hline Daya Ingat & 0 & 16,67 & 83,33 & 100 \\
\hline $\begin{array}{l}\text { Pengertian } \\
\text { Tentang } \\
\text { Objek dan } \\
\text { Penilaian } \\
\text { Terhadap } \\
\text { Situasi }\end{array}$ & 0 & 16,67 & 83,33 & 100 \\
\hline $\begin{array}{l}\text { Memahami } \\
\text { Cerita }\end{array}$ & 16,67 & 0 & 83,33 & 100 \\
\hline $\begin{array}{l}\text { Gambar } \\
\text { Orang }\end{array}$ & 100 & 0 & 0 & 100 \\
\hline
\end{tabular}

Berdasarkan perolehan data dari hasil tes NST pada Tabel 2 terlihat bahwa seluruh murid yang berusia 4 tahun (100\%) telah mampu untuk melakukan tugas pengamatan bentuk dan membedakan. Selain itu, keenam orang murid juga sudah memiliki konsentrasi yang baik ketika mengerjakan tugas yang membutuhkan fokus dengan batasan waktu untuk mencari benda yang sama. Sedangkan pada aspek motorik halus, pengertian tentang besar jumlah dan perbandingan, pengamatan tajam, pengamatan kritis, daya ingat, pengertian tentang objek dan penilaian terhadap situasi, serta memahami cerita terlihat berbeda-beda. Ada murid yang belum siap, ada yang masih diragukan kesiapannya, dan ada yang benar-benar siap. Sementara untuk subtes menggambar orang, hampir keseluruhan murid $(100 \%)$ terlihat belum mampu menggambar orang dengan baik. Artinya, mereka belum mengenali diri dan memahami fungsi tubuhnya dengan baik. 
Tabel 3. Gambaran Hasil NST Murid Kayata School yang Berusia 5 Tahun

\begin{tabular}{|c|c|c|c|c|}
\hline Aspek NST & $\begin{array}{l}\text { Belum } \\
\text { Siap } \\
(\%)\end{array}$ & $\begin{array}{c}\text { Ragu } \\
(\%)\end{array}$ & $\begin{array}{c}\text { Siap } \\
\text { Untuk } \\
\text { Sekolah } \\
(\%)\end{array}$ & $\begin{array}{c}\text { Total } \\
(\%)\end{array}$ \\
\hline $\begin{array}{l}\text { Pengamatan } \\
\text { Bentuk dan } \\
\text { Kemampuan } \\
\text { Membedakan }\end{array}$ & 0 & 0 & 100 & 100 \\
\hline $\begin{array}{l}\text { Motorik } \\
\text { Halus }\end{array}$ & 0 & 25 & 75 & 100 \\
\hline $\begin{array}{l}\text { Pengertian } \\
\text { Tentang } \\
\text { Besar Jumlah } \\
\text { dan } \\
\text { Perbandingan }\end{array}$ & 0 & 50 & 50 & 100 \\
\hline $\begin{array}{l}\text { Pengamatan } \\
\text { Tajam }\end{array}$ & 25 & 25 & 50 & 100 \\
\hline $\begin{array}{l}\text { Pengamatan } \\
\text { Kritis }\end{array}$ & 0 & 25 & 75 & 100 \\
\hline Konsentrasi & 0 & 25 & 75 & 100 \\
\hline Daya Ingat & 25 & 0 & 75 & 100 \\
\hline $\begin{array}{l}\text { Pengertian } \\
\text { Tentang } \\
\text { Objek dan } \\
\text { Penilaian } \\
\text { Terhadap } \\
\text { Situasi } \\
\end{array}$ & 25 & 0 & 75 & 100 \\
\hline $\begin{array}{l}\text { Memahami } \\
\text { Cerita }\end{array}$ & 25 & 0 & 75 & 100 \\
\hline $\begin{array}{l}\text { Gambar } \\
\text { Orang }\end{array}$ & 75 & 0 & 25 & 100 \\
\hline
\end{tabular}

Berdasarkan perolehan data dari hasil tes NST pada Tabel 3 terlihat bahwa seluruh murid yang berusia 5 tahun (100\%) juga telah mampu untuk melakukan tugas pengamatan bentuk dan membedakan. Sedangkan pada aspek motorik halus, pengertian tentang besar jumlah dan perbandingan, pengamatan tajam, pengamatan kritis, daya ingat, pengertian tentang objek dan penilaian terhadap situasi, serta memahami cerita terlihat berbeda-beda. Ada murid yang belum siap, ada yang masih diragukan kesiapannya, dan ada yang benar-benar siap. Sementara untuk subtes menggambar orang, tiga orang murid $(75 \%)$ terlihat belum mampu menggambar orang dengan baik. Sedangkan satu orang lainnya (25\%). Artinya, sudah cukup mampu mengenali diri dan memahami fungsi tubuhnya dengan baik.

Tabel 4. Gambaran Hasil NST Murid Kayata School yang Berusia 6 Tahun

\begin{tabular}{|c|c|c|c|c|}
\hline Aspek NST & $\begin{array}{l}\text { Belum } \\
\text { Siap } \\
(\%)\end{array}$ & $\begin{array}{c}\text { Ragu } \\
(\%)\end{array}$ & $\begin{array}{c}\text { Siap } \\
\text { Untuk } \\
\text { Sekolah } \\
(\%)\end{array}$ & $\begin{array}{c}\text { Total } \\
(\%)\end{array}$ \\
\hline $\begin{array}{l}\text { Pengamatan } \\
\text { Bentuk dan } \\
\text { Kemampuan } \\
\text { Membedakan }\end{array}$ & 0 & 0 & 100 & 100 \\
\hline $\begin{array}{l}\text { Motorik } \\
\text { Halus } \\
\end{array}$ & 0 & 0 & 100 & 100 \\
\hline $\begin{array}{l}\text { Pengertian } \\
\text { Tentang } \\
\text { Besar Jumlah } \\
\text { dan } \\
\text { Perbandingan }\end{array}$ & 0 & 25 & 75 & 100 \\
\hline $\begin{array}{l}\text { Pengamatan } \\
\text { Tajam }\end{array}$ & 25 & 0 & 75 & 100 \\
\hline $\begin{array}{l}\text { Pengamatan } \\
\text { Kritis }\end{array}$ & 0 & 0 & 100 & 100 \\
\hline Konsentrasi & 0 & 0 & 100 & 100 \\
\hline Daya Ingat & 0 & 0 & 100 & 100 \\
\hline $\begin{array}{l}\text { Pengertian } \\
\text { Tentang } \\
\text { Objek dan } \\
\text { Penilaian } \\
\text { Terhadap } \\
\text { Situasi }\end{array}$ & 0 & 0 & 100 & 100 \\
\hline $\begin{array}{l}\text { Memahami } \\
\text { Cerita }\end{array}$ & 0 & 0 & 100 & 100 \\
\hline $\begin{array}{l}\text { Gambar } \\
\text { Orang }\end{array}$ & 50 & 0 & 50 & 100 \\
\hline
\end{tabular}

Berdasarkan perolehan data dari hasil tes NST pada Tabel 4 terlihat bahwa seluruh murid yang berusia 6 tahun (100\%) juga telah mampu untuk melakukan tugas pengamatan bentuk dan 
membedakan. Keempat murid yang berusia 6 tahun tersebut juga telah terampil menggunakan alat tulis, mampu menilai kondisi atau situasi yang dirasa kurang atau belum lengkap, fokus terhadap tugas yang dikerjakan, mampu mengingat kembali stimulus gambar yang telah disajikan sebelumnya, mampu memahami aturan dan penilaian sosial, dan mampu memahami cerita dengan baik. Hal ini terlihat pada masing-masing aspek NST, yakni motorik halus, pengamatan kritis, konsentrasi, daya ingat, pengertian tentang objek dan penilaian terhadap situasi, serta memahami cerita. Aspek yang tergolong sedikit dikuasai oleh kelompok murid berusia 6 tahun adalah menggambar orang. Hanya dua dari empat orang (50\%) yang sudah mampu mengenali anggota tubuhnya dengan baik.

\section{Tabel 5. Gambaran Hasil NST Murid Kayata School yang Berusia} 7 Tahun

\begin{tabular}{|l|c|c|c|c|}
\hline Aspek NST & $\begin{array}{c}\text { Belum } \\
\text { Siap } \\
(\%)\end{array}$ & $\begin{array}{c}\text { Ragu } \\
(\%)\end{array}$ & $\begin{array}{c}\text { Siap } \\
\text { Untuk } \\
\text { Sekolah } \\
(\%)\end{array}$ & $\begin{array}{c}\text { Total } \\
(\%)\end{array}$ \\
\hline $\begin{array}{l}\text { Pengamatan } \\
\text { Bentuk dan } \\
\text { Kemampuan } \\
\text { Membedakan }\end{array}$ & 0 & 0 & 100 & 100 \\
\hline $\begin{array}{l}\text { Motorik } \\
\text { Halus }\end{array}$ & 0 & 0 & 100 & 100 \\
\hline $\begin{array}{l}\text { Pengertian } \\
\text { Tentang } \\
\text { Besar Jumlah } \\
\text { dan } \\
\text { Perbandingan }\end{array}$ & 0 & 0 & 100 & 100 \\
\hline $\begin{array}{l}\text { Pengamatan } \\
\text { Tajam }\end{array}$ & 0 & 0 & 100 & 100 \\
\hline $\begin{array}{l}\text { Pengamatan } \\
\text { Kritis }\end{array}$ & 0 & 0 & 100 & 100 \\
\hline Konsentrasi & 0 & 0 & 100 & 100 \\
\hline Daya Ingat & 0 & 0 & 100 & 100 \\
\hline $\begin{array}{l}\text { Pengertian } \\
\text { Tentang } \\
\text { Objek dan } \\
\text { Penilaian } \\
\text { Terhadap }\end{array}$ & 0 & 0 & 100 & 100 \\
\hline
\end{tabular}

\begin{tabular}{|l|c|c|c|c|}
\hline Situasi & & & & \\
\hline $\begin{array}{l}\text { Memahami } \\
\text { Cerita }\end{array}$ & 0 & 0 & 100 & 100 \\
\hline $\begin{array}{l}\text { Gambar } \\
\text { Orang }\end{array}$ & 0 & 100 & 0 & 100 \\
\hline
\end{tabular}

Berdasarkan perolehan data dari hasil tes NST pada Tabel 5 terlihat bahwa seorang murid yang telah berusia 7 tahun $(100 \%)$ telah sangat siap untuk mengikuti pendidikan di sekolah dasar. Ia sudah menguasai hampir seluruh aspek yang diukur menggunakan NST. Hanya satu aspek saja, yakni kemampuan menggambar orang, yang masih belum berkembang secara optimal.

Dari penjabaran data NST berdasarkan kelompok usia murid Kayata School Berastagi, yakni 4, 5, 6, dan 7 tahun, dapat ditarik kesimpulan bahwa semakin bertambah usia anak prasekolah, maka semakin banyak aspek kesiapan sekolah yang dikuasai, khususnya kesiapan intelektual. Didukung dengan proses belajar yang mereka dapatkan di sekolah, mereka mampu berpikir kritis, mengamati secara tajam, mengingat informasi, dan berkonsentrasi saat mengerjakan tugas. Sementara kesiapan motorik, sosial, dan emosi masih belum optimal. Hal ini dapat terlihat dari aspek gambar orang, yang meminta murid untuk menggambarkan orang lengkap. Semakin lengkap dan jelas gambar orang yang digambar, maka semakin matang juga perkembangan motorik, sosial, dan emosi anak. Sedangkan dari hasil perolehan data diketahui bahwa murid yang berusia 7 tahun pun belum dapat menggambarkan orang dengan tepat. 
Tabel 6. Gambaran Age-Equivalent (AE) Berdasarkan VABS Murid Kayata School

\begin{tabular}{|c|c|c|c|c|}
\hline $\begin{array}{c}\text { Nam } \\
\text { a } \\
\text { Muri } \\
\text { d } \\
\text { (Inisi } \\
\text { al) }\end{array}$ & $\begin{array}{c}\text { Usia } \\
\text { Kron } \\
\text { ologis }\end{array}$ & $\begin{array}{c}\text { AE } \\
\text { Komuni } \\
\text { kasi }\end{array}$ & $\begin{array}{c}\text { AE } \\
\text { Keteram } \\
\text { pilan } \\
\text { Hidup } \\
\text { Sehari- } \\
\text { hari }\end{array}$ & $\begin{array}{c}\text { AE } \\
\text { Sosiali } \\
\text { sasi }\end{array}$ \\
\hline AI & 4 & 2 & 4 & 3 \\
\hline AD & 4 & 2 & 2 & 5 \\
\hline AL & 4 & $3-4$ & 4 & 5 \\
\hline AN & 4 & 4 & 2 & 5 \\
\hline BR & 4 & 2 & 2 & 3 \\
\hline KI & 4 & 5 & 4 & 4 \\
\hline ST & 5 & 2 & 7 & 6 \\
\hline EM & 5 & $3-4$ & 4 & $4-5$ \\
\hline JE & 5 & 2 & 4 & 3 \\
\hline RA & 5 & $3-4$ & 6 & $7-8$ \\
\hline ALD & 6 & 5 & 6 & 5 \\
\hline AR & 6 & $7-8$ & 7 & $7-8$ \\
\hline DI & 6 & 6 & 7 & 5 \\
\hline JO & 6 & $7-8$ & 4 & 5 \\
\hline SH & 7 & $7-8$ & 6 & 6 \\
\hline
\end{tabular}

Hasil pemeriksaan menggunakan NST, diperkuat juga oleh hasil perolehan data menggunakan VABS. Berdasarkan Tabel 6 di atas, terlihat sejauhmana perkembangan kemampuan adaptif masing-masing murid bila dibandingkan dengan usia kronologisnya. Pada domain 'Komunikasi', hanya ada enam orang murid (40\%) yang memiliki kemampuan komunikasi reseptif, ekspresif, dan tertulis setara dan di atas usia kronologisnya. Mereka antara lain: antara lain: AL, KI, AR, DI, JO, dan SH. Sedangkan sembilan orang lainnya (60\%) memiliki kemampuan komunikasi yang tergolong di bawah usia kronologisnya.

Demikian juga dalam domain 'Keterampilan Hidup Sehari-hari', hanya enam orang murid $(40 \%)$ yang telah memiliki keterampilan personal (seperti: makan, berpakaian, dsb), domestik (seperti: menyimpan barang, ke toilet sendiri pada malam hari, dsb), dan masyarakat (seperti: paham akan fungsi jam, fungsi uang, dsb) setara dan di atas usia kronologisnya. Mereka antara lain: AL, ST, RA, ALD, AR, dan DI. Sedangkan enam orang lainnya $(60 \%)$ memiliki keterampilan hidup yang tergolong di bawah usia kronologisnya.

Sementara dalam domain 'Sosialisasi', hanya tujuh orang murid $(46,67 \%)$ yang telah mampu berinteraksi dengan orang lain (hubungan antar personil), menggunakan waktu luang dengan baik (bermain dan waktu senggang), bertanggung jawab serta peka terhadap orang lain (keterampilan mengatasi) setara dan di atas usia kronologisnya. Mereka antara lain: AD, AL, AN, ST, EM, RA, dan AR. Sedangkan delapan orang lainnya $(53,33 \%)$ memiliki keterampilan hidup yang tergolong di bawah usia kronologisnya.

Berdasarkan data VABS yang dijabarkan tersebut, dapat diketahui bahwa hampir setengah dari keseluruhan murid Kayata School memiliki kemampuan sosial yang belum optimal. Hal ini sejalan dengan hasil dari pemeriksaan dengan NST, dimana kebanyakan murid telah memiliki kesiapan intelektual untuk memasuki sekolah dasar, namun secara sosial dan emosi masih dapat dikatakan belum siap untuk mengikuti kegiatan belajar di sekolah dasar. Padahal kesiapan bersekolah tidak hanya meliputi halhal yang berkaitan dengan kecerdasan atau intelektual saja, tetapi juga mencakup aspek yang lebih luas, yaitu aspek sosial dan 
emosional (Haditono, 1986). Kesiapan sosial diperlukan agar anak mudah menyesuaikan diri dengan harapan-harapan dan aturan-aturan di sekolah. Apabila anak memiliki kesiapan sekolah, ia akan cukup matang serta sadar akan status dirinya, sehingga tidak menuntut perhatian terus menerus, mau menang sendiri, tetapi harus mampu melaksanakan tugas dari guru serta mampu menerima kewibawaan guru.

Sedangkan anak yang secara emosional sudah siap bersekolah ditandai dengan kemandiriannya lepas dari bantuan dan bimbingan orang dewasa, tidak mengalami kesulitan untuk berpisah dalam waktu tertentu dengan orangtuanya, dapat menerima dan mengerti setiap tuntutan di sekolah, serta dapat mengontrol emosinya seperti rasa marah, takut, dan iri (Hurlock dalam Sulistyaningsih, 2005). Selain itu anak juga harus sudah dapat bekerja sama, saling menolong, menunggu giliran untuk suatu tugas, dan sebagainya (Margolin dalam Sulistyaningsih, 2005).

\section{KESIMPULAN}

Berdasarkan $\begin{array}{r}\text { hasil } \\ \text { pemeriksaan kesiapan }\end{array}$
menggunakan NST dan kematangan
sosial menggunakan VABS terhadap
murid-murid Kayata School,
disimpulkan bahwa seiring semakin
matang usia anak prasekolah dan
didukung dengan proses belajar di
sekolah, maka semakin banyak aspek
kesiapan sekolah yang dikuasai oleh,
khususnya kesiapan intelektual.
Sementara kesiapan motorik, sosial,
dan emosi terlihat masih belum
optimal. Dengan kata lain, murid-

murid prasekolah Kayata School telah memiliki kesiapan intelektual untuk memasuki sekolah dasar, namun secara sosial dan emosi masih dapat dikatakan belum siap untuk mengikuti kegiatan belajar di sekolah dasar.

\section{SARAN}

Berkaitan dengan hasil penelitian, maka penelit mengajukan beberapa saran, diantaranya:

1. Bagi orangtua, diharapkan untuk terus memberikan stimulasi bagi anak agar kematangan sosial dan emosi anak dapat lebih optimal. Hal yang dapat dilakukan adalah mengurangi pemberian bantuan secara bertahap, meluangkan waktu untuk membaca dan berdiskusi dengan anak, meluangkan waktu untuk bermain dengan anak, dan melatih anak untuk mengendalikan emosi.

2. Orangtua juga perlu mempertimbangkan usia anak saat memasuki sekolah dasar agar mereka lebih produktif dan bertanggung jawab atas perilaku mereka saat berada di sekolah dasar. Membantu anak untuk belajar bertanggung jawab terhadap perilaku mereka sendiri sama pentingnya dengan membantu mereka belajar membaca dan menulis.

3. Bagi guru dan pihak sekolah, perlu memberikan stimulasi yang seimbang bagi berbagai aspek perkembangan anak, termasuk aspek sosial dan emosi. Guru juga perlu mengoptimalkan kemampuan anak dalam mengenali diri dan 
fungsi tubuh, agar anak dapat lebih mandiri ketika memasuki sekolah dasar.

4. Bagi peneliti selanjutnya, dapat meneliti bagaimana kesiapan sekolah anak ditinjau dari jenis kelamin, status pernikahan orangtua, maupun tingkat pendidikan orangtua.

\section{DAFTAR PUSTAKA}

Chaplin, J.P. (1989). Dictionary of Psychology. New York: Dell Publishing Co.

Haditono, S.R. (1986). Pengasuhan Anak Menuju Kesiapan Masuk Sekolah Dasar (SD). Yogyakarta: Fakultas Psikologi Universitas Gajah Mada.

Hurlock, E.B. (1980). Psikologi Perkembangan: Suatu Pendekatan Sepanjang Rentang Kehidupan Edisi Ke-5. Jakarta: Erlangga.

Lerner, J.W. (1997). Learning Disabilities: Theories, Diagnosis, and Teaching Strategies 7th Edition. Boston: Houghton Mifflin Co.

Novitawati. (2013). Kesiapan Sekolah Anak Taman Kanak-kanak Berbasis Model Pembelajaran Sentra (Studi Kualitatif di Taman Kanak-kanak Islam Sabilal Muhtadin Banjarmasin Tahun 2011). Jurnal Pendidikan Usia Dini Volume 7, Edisi 1 April 2013 Hal 109-132.

Sembiring, R.A. (2013). Kesiapan Masuk Sekolah Dasar Ditinjau Dari NST, Emosi, dan Sosial. Proceeding Temu Ilmiah
Nasional Pendidikan Anak Usia Dini 2012: Identifikasi Perkembangan Psikologis Anak Usia Dini. Salatiga: Universitas Kristen Satya Wacana.

Sparrow, S., Bella, D. \& Cicchetti, D. (1984). Vineland Adaptive Behavior Scales. Circle Pines, $\mathrm{MN}$ : American Guidance Services.

Sudaryono. (2016). Metode Penelitian Pendidikan. Jakarta: Kencana.

Sugiyono. (2012). Metode Penelitian Kuantitatif dan Kualitatif. Bandung: Alfabeta.

Sulistyaningsih, W. (2005). Kesiapan Bersekolah Ditinjau Dari Jenis Pendidikan Pra Sekolah Anak dan Tingkat Pendidikan Orangtua. Psikologia Volume I, Edisi Juni 2005 No. 1, Hal 1-8.

Syah, M. (1997). Psikologi Pendidikan: Dengan Pendekatan Baru: Bandung: PT Remaja Rosdakarya.

UNICEF. (2012). School Readiness, a Conceptual Framework. New York: UNICEF. 